\title{
Antioxidant Activity and Volatile and Phenolic Profiles of Essential Oil and Different Extracts of Wild Mint (Mentha longifolia) from the Pakistani Flora
}

\author{
Tahseen Iqbal, Abdullah Ijaz Hussain, Shahzad Ali Shahid Chatha, \\ Syed Ali Raza Naqvi, and Tanveer Hussain Bokhari
}

Institute of Chemistry, Government College University Faisalabad, Faisalabad 38000, Pakistan

Correspondence should be addressed to Abdullah Ijaz Hussain; abdullahijaz@gcuf.edu.pk

Received 29 May 2013; Revised 13 August 2013; Accepted 28 August 2013

Academic Editor: Shao-Nong Chen

Copyright ( $\odot 2013$ Tahseen Iqbal et al. This is an open access article distributed under the Creative Commons Attribution License, which permits unrestricted use, distribution, and reproduction in any medium, provided the original work is properly cited.

\begin{abstract}
The antioxidant activity and free radical scavenging capacity of the essential oil and three different extracts of wildly grown Mentha longifolia (M. longifolia) were studied. The essential oil from $M$. longifolia aerial parts was isolated by hydrodistillation technique using Clevenger-type apparatus. The extracts were prepared with three solvents of different polarity ( $n$-hexane, dichloromethane, and methanol) using Soxhlet extractor. Maximum extract yield was obtained with methanol $(12.6 \mathrm{~g} / 100 \mathrm{~g})$ while the minimum with dichloromethane $(3.50 \mathrm{~g} / 100 \mathrm{~g})$. The essential oil content was found to be $1.07 \mathrm{~g} / 100 \mathrm{~g}$. A total of 19 constituents were identified in the M. longifolia oil using GC/MS. The main components detected were piperitenone oxide, piperitenone, germacrene $\mathrm{D}$, borneol, and $\beta$-caryophyllene. The total phenolics (TP) and total flavonoids (TF) contents of the methanol extract of $M$. longifolia were found to be significantly higher than dichloromethane and hexane extracts. The dichloromethane and methanol extracts exhibited excellent antioxidant activity as assessed by $2,2^{\prime}$-diphenyl-1-picrylhydrazyl (DPPH) free radical scavenging ability, bleaching $\beta$-carotene, and inhibition of linoleic acid peroxidation assays. The essential oil and hexane extract showed comparatively weaker antioxidant and free radical scavenging activities. The results of the study have validated the medicinal and antioxidant potential of $M$. longifolia essential oil and extracts.
\end{abstract}

\section{Introduction}

Free radicals are considered to initiate oxidation that leads to aging and causes diseases in human beings $[1,2]$. Moreover, activated oxygen incorporates reactive oxygen species (ROS) which consists of free radicals $\left({ }^{1} \mathrm{O}_{2}, \mathrm{O}_{2}{ }^{--},{ }^{\circ} \mathrm{OH}, \mathrm{ONOO}^{-}\right)$ and nonfree radicals $\left(\mathrm{H}_{2} \mathrm{O}_{2}, \mathrm{NO}\right.$, and $\left.\mathrm{R}-\mathrm{OOH}\right)$ [3]. ROS are liberated by virtue of stress, and thus, an imbalance is developed in the body that damages cells in it and causes health problems $[2,4]$. Moreover, oxidation in processed foods, enriched with fats and oils, during storage leads to spoilage and quality deterioration [5].

The use of synthetic antioxidants such as butylated hydroxyanisole (BHA), and butylated hydroxytoluene (BHT) and tertiary butylhydroquinone (TBHQ) have been restricted because of their carcinogenicity and other toxic properties $[3,6]$. Thus, the interest in natural antioxidants has increased considerably. Natural antioxidants can be phenolic compounds (tocopherols, flavonoids, and phenolic acids) and carotenoids (lutein, lycopene, and carotene). Growing evidence has shown an inverse correlation between the intake of dietary antioxidants and the risk of chronic diseases such as coronary heart disease, cancer, and several other agingrelated health concerns $[1,7]$.

Natural antioxidant compounds exhibit their antioxidant activity by various mechanisms including chain breaking by donation of hydrogen atoms or electrons that convert free radicals into more stable species and decomposing lipid peroxides into stable final products [1]. Different in vitro assays simply provide an idea of the protective efficacy of the test model. Thus it is necessary to use at least two methods depending on the expected antioxidant potential and/or on the origin of the substance. Most commonly used methods for the determination of antioxidant activity of plant 
essential oils and extracts are 2,2-di(4-tert-octaphenyl)-1picrylhydrazyl ( $\left.\mathrm{DPPH}^{*}\right)$ radical scavenging assay, inhibition of linoleic acid peroxidation, and bleaching of $\beta$-carotene in linoleic acid system assays. DPPH radical scavenging assay is the most popular and frequently used for the determination of antioxidant activity of essential oils and plant extracts $[1,7,8]$. Bleachability of $\beta$-carotene in linoleic acid system is another simple, reproducible, and time efficient method for rapid evaluation of antioxidant properties $[1,7,8]$. Measurement of inhibition of linoleic acid peroxidation is also an effective method for the assessment of antioxidant activity of the plant samples.

Mentha longifolia (wild mint) belongs to genus Mentha (family Lamiaceae) and grows widely throughout the temperate regions of the world [8]. The different herbal and food products from Mentha species have been in use since ancient times for the treatment of heart burns, indigestion, colic, flatulence, coughs and flu, nausea, irritable bowel syndrome, gall-bladder and bile ducts, herpes, and certain skin infections including acne and pigmentation [7-9]. Research work on plants from different regions resulted in the innovation of biologically active substances $[8,10]$. Therefore the study was conducted to investigate the chemical composition and antioxidant and antimicrobial activities of essential oil and three different extracts from $M$. longifolia native to dry region of Pakistan.

\section{Materials and Methods}

2.1. Collection and Pretreatment of Plant Material. Aerial parts of wild mint ( $M$. longifolia L.) were collected during May-June from South Punjab, Pakistan. The specimens were further identified and authenticated by a taxonomist, Dr. Qasim Ali (Assistant Professor), Department of Botany, Government College University Faisalabad. Collected specimens were dried at $35^{\circ} \mathrm{C}$ in a hot air oven (IM-30 Irmec, Germany) and grinded to 80 mesh and stored in polyethylene bags at $-4^{\circ} \mathrm{C}$.

2.2. Chemicals and Reagents. Linoleic acid, $2,2^{\prime}$-diphenyl-1picrylhydrazyl, gallic acid, Folin-Ciocalteu reagent, ascorbic acid, trichloroacetic acid, sodium nitrite, aluminum chloride, ammonium thiocyanate, ferrous chloride, ferric chloride, potassium ferricyanide, butylated hydroxytoluene (99.0\%), and homologous series of $\mathrm{C}_{9}-\mathrm{C}_{24} n$-alkanes and various reference chemicals used to identify the constituents were obtained from Sigma Chemical Co. (St. Louis, MO, USA). All other chemicals (analytical grade), that is, anhydrous sodium carbonate ferrous chloride, ammonium thiocyanate, chloroform, and methanol, used in this study were purchased from Merck (Darmstadt, Germany), unless stated otherwise. All culture media and standard antibiotic discs were purchased from Oxoid Ltd. (Hampshire, UK).

2.3. Isolation of Essential Oil. The oven-dried and ground fennel seeds ( 80 mesh) were subjected to hydrodistillation for $4 \mathrm{~h}$, using a Clevenger-type apparatus. The obtained essential oil was dried over anhydrous sodium sulfate, filtered, and stored at $-4^{\circ} \mathrm{C}$ until analyzed.
2.4. Preparation of Extracts. Ground ( 80 mesh) M. longifolia sample $(100 \mathrm{~g})$ was subjected to extraction for $4 \mathrm{~h}$ using Soxhlet unit. The plant materials were extracted in sequence with three solvents of different polarity, that is, $n$-hexane, dichloromethane and methanol. The extracts were concentrated under vacuum at $45^{\circ} \mathrm{C}$, using a vacuum rotary evaporator (N-N Series, Eyela, Rikakikai Co. Ltd., Tokyo, Japan), and stored at $-4^{\circ} \mathrm{C}$ until used for further analyses.

\subsection{Analysis of the Essential Oil}

2.5.1. Gas Chromatography/Mass Spectrometry Analysis. The M. longifolia essential oil composition was determined on Agilent-Technologies (Little Falls, CA, USA) 6890N Network gas chromatographic (GC) system, equipped with an AgilentTechnologies 5975 inert XL Mass selective detector and Agilent-Technologies 7683B series autoinjector. Compounds were separated on HP-5 MS capillary column $(30 \mathrm{~m} \times$ $0.25 \mathrm{~mm}$, film thickness $0.25 \mu \mathrm{m}$; Little Falls, CA, USA). A sample of $1.0 \mu \mathrm{L}$ was injected in the split mode with split ratio 1:100. Helium was used as a carrier gas at a flow rate of $1.5 \mathrm{~mL} / \mathrm{min}$. For GC/MS detection, an electron ionization system, with ionization energy of $70 \mathrm{eV}$, was used. The column oven temperature was programmed from $80^{\circ} \mathrm{C}$ to $220^{\circ} \mathrm{C}$ at the rate of $4^{\circ} \mathrm{C} / \mathrm{min}$; initial and final temperatures were held for 3 and $10 \mathrm{~min}$, respectively. Mass scanning range was $50-550 \mathrm{~m} / z$ while the injector and MS transfer line temperatures were set at 220 and $290^{\circ} \mathrm{C}$, respectively. All quantifications were done by a built-in data-handling program of the equipment used (Perkin-Elmer, Norwalk, CT, USA). The composition was reported as a relative percentage of the total peak area.

2.5.2. Compounds Identification. The components of the $M$. longifolia essential oil were identified by comparison of their retention indices relative to $\left(\mathrm{C}_{9}-\mathrm{C}_{24}\right) n$-alkanes either with those of published data or with authentic compounds [11, 12]. Compounds were further identified and authenticated using their complete mass fragmentation data compared to the NIST02.L and WILEY7n.L mass spectral libraries and published mass spectra and, wherever possible, by coinjection with authentic standards $(\alpha$-pinene, $\beta$-pinene, limonene, cis- $\beta$-ocimene, $\delta$-terpinene, 1,8-cineol, linalool, borneol, $\alpha$-terpineol, thymol, piperitenone, piperitenone oxide, $\beta$ caryophyllene, germacrene $\mathrm{D}$, calamenene, cis-jasmone, and caryophyllene oxide) $[1,13,14]$.

\subsection{Antioxidant Activity}

2.6.1. Determination of Total Phenolics (TP) and Total Flavonoids (TF) Contents. Amounts of total phenolics (TP) and total flavonoids (TF) in the $M$. longifolia extracts were determined using Folin-Ciocalteu reagent method and aluminum chloride colorimetric assay, respectively, as reported previously [15].

2.6.2. DPPH Radical Scavenging Assay. 2,2'-Diphenyl-1picrylhydrazyl (DPPH) free radical assay was carried out to measure the free radical scavenging activity as reported 
previously [9]. Briefly, M. longifolia essential oil, extracts, piperitenone compound, and BHT concentrations in methanol $(1-100 \mu \mathrm{g} / \mathrm{mL})$ were mixed with $2 \mathrm{~mL}$ of $90 \mu \mathrm{M}$ methanol solution of DPPH. After $30 \mathrm{~min}$ incubation period at room temperature, the absorbance was read at $517 \mathrm{~nm}$. The scavenging (\%) was calculated by the following formula:

$$
\text { Scavenging }(\%)=100 \times\left\{\frac{\left(A_{\text {blank }}-A_{\text {sample }}\right)}{A_{\text {blank }}}\right\},
$$

where $A_{\text {blank }}$ is the absorbance of the DPPH solution and $A_{\text {sample }}$ is the absorbance of the extract solution. Extract concentration providing $50 \%$ scavenging $\left(\mathrm{IC}_{50}\right)$ was calculated from the graph plotted between scavenging percentage and extract concentration.

2.6.3. Antioxidant Activity Determination in Linoleic Acid System. The antioxidant activity of $M$. longifolia essential oil and extracts weas determined in terms of measurement of $\%$ inhibition of peroxidation in linoleic acid system following the reported method with some modification [16]. Essential oil and extracts $(5 \mathrm{mg})$ were added to a solution mixture of linoleic acid $(0.13 \mathrm{~mL}), 99.8 \%$ ethanol $(10 \mathrm{~mL})$, and $10 \mathrm{~mL}$ of $0.2 \mathrm{M}$ sodium phosphate buffer $(\mathrm{pH} 7)$. Total mixture was diluted to $25 \mathrm{~mL}$ with distilled water. The solution was incubated at $40^{\circ} \mathrm{C}$ for $175 \mathrm{~h}$. The extent of oxidation was measured by peroxide value using the colorimetric method as reported previously [15].

2.6.4. Bleaching of $\beta$-Carotene in Linoleic Acid System. Antioxidant activity of $M$. longifolia essential oil and extracts was also assessed by bleaching of $\beta$-carotene/linoleic acid emulsion system as reported previously [1]. Briefly, a stock solution of $\beta$-carotene-linoleic acid mixture was prepared by dissolving $0.1 \mathrm{mg} \beta$-carotene, $20 \mathrm{mg}$ linoleic acid, and $100 \mathrm{mg}$ Tween $40 \mathrm{in} 1.0 \mathrm{~mL}$ of chloroform (HPLC grade). The chloroform was removed under vacuum in rotary evaporator at $50^{\circ} \mathrm{C}$. Then, $50 \mathrm{~mL}$ of distilled water saturated with oxygen (30 min, $100 \mathrm{~mL} \mathrm{~min}^{-1}$ ) was added with vigorous shaking. A $5.0 \mathrm{~mL}$ of this reaction mixture was dispensed to test tubes with $200 \mu \mathrm{L}$ of the essential oil or trans-anethole solution, prepared at $4.0 \mathrm{~g} \mathrm{~L}^{-1}$ concentrations, and the absorbance was immediately $(t=0)$ measured at $490 \mathrm{~nm}$ against a blank, consisting of an emulsion without $\beta$-carotene. Then emulsion was incubated for $50 \mathrm{~h}$ at room temperature, and the absorbance was recorded at different time intervals. The same procedure was repeated with BHT and blank. Antioxidant capacities of the fennel essential oils were compared with BHT and blank.

2.7. Statistical Analysis. All the experiments were conducted in triplicate unless stated otherwise, and data are presented as mean \pm standard deviation (SD). Statistical analysis of the data was performed by Analysis of Variance (ANOVA) using STATISTICA 5.5 (Stat Soft Inc, Tulsa, OK, USA) software, and probability value $P \leq 0.05$ was considered to denote a statistically significant difference.
TABLE 1: Yield of M. longifolia essential oil and hexane, dichloromethane, and methanol extracts.

\begin{tabular}{lc}
\hline Samples & Yield $(\mathrm{g} / 100 \mathrm{~g})^{*}$ \\
\hline Essential oil & $1.07 \pm 0.10^{\mathrm{a}}$ \\
$n$-Hexane extract & $7.30 \pm 0.32^{\mathrm{c}}$ \\
Dichloromethane extract & $3.50 \pm 0.21^{\mathrm{b}}$ \\
Methanol extract & $12.60 \pm 0.70^{\mathrm{d}}$ \\
\hline
\end{tabular}

${ }^{*}$ Values are mean \pm SD of three samples of $M$. longifolia analyzed individually in triplicate.

Different letters in superscript represent significant $(P<0.05)$ difference within solvents.

\section{Results and Discussion}

3.1. Percentage Yield of Essential Oil and Different Extracts. Yield (g/100 g of dry plant material) of Mentha longifolia essential oil and $n$-hexane, dichloromethane, and methanol extracts is given in Table 1. Maximum yield was obtained with methanol $(12.60 \mathrm{~g} / 100 \mathrm{~g})$. The minimum yield was obtained with dichloromethane $(3.50 \mathrm{~g} / 100 \mathrm{~g})$. The essential oil yield from the aerial parts of $M$. longifolia was found to be $1.07 \mathrm{~g} / 100 \mathrm{~g}$. Nonpolar extract yield ( $n$-hexane) was found to be $7.30 \mathrm{~g} / 100 \mathrm{~g}$. Tukey's range test revealed the significant $(P<0.05)$ difference among the extract yield with solvents of different polarities. Differences in yield of extracts from different solvents might be attributed to the availability of extractable component of different polarities.

3.2. Essential Oil Composition. The retention indices, percentage composition, and identification methods for the essential oil of $M$. longifolia are given in Table 2. Nineteen compounds, $96.79 \%$ of the total oil, were identified from the oil (Figure 1). The most abundant constituents ( $>5 \%$ ) in the essential oil of $M$. longifolia were found to be piperitenone oxide (28.3\%), piperitenone $(24.9 \%)$, germacrene D (8.16\%), borneol (5.96\%), and $\beta$-caryophyllene (5.94\%). Analyzed essential oil mainly consisted of oxygenated monoterpenes (67.24\%) followed by sesquiterpene hydrocarbons (17.19\%), monoterpene hydrocarbons $(7.31 \%)$, and oxygenated sesquiterpenes (5.05\%).

The variation in the essential oil composition of $M$. longifolia is reported in the literature from different part of the world $[8,17,18]$. Our results reported the essential oil composition of $M$. longifolia essential oil from South Punjab, Pakistan, where the weather conditions are very hot and dry. Variations in the chemical compositions of essential oil across countries might be attributed to the varied agroclimatic (climatical, seasonal, and geographical) conditions of the regions, isolation regimes, and adaptive metabolism of plants.

\subsection{Antioxidant Activity}

3.3.1. Total Phenolics (TP) and Total Flavonoids (TF) Contents. Amount of total phenolics and total flavonoids is given in Figure 2. The highest TP was found in methanol extract $(71.43 \mathrm{mg} / \mathrm{g}$ acid of dry plant material, measured as gallic equivalent) and the lowest in hexane extract $(1.7 \mathrm{mg} / \mathrm{g}$ acid of dry plant material, measured as gallic equivalent). Similarly, 


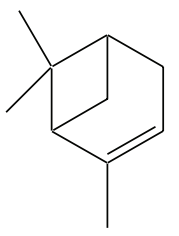

(a)<smiles>C=C1CCC2CC1C2(C)C</smiles>

(b)<smiles>C=C(C)C1CC=C(C)CC1</smiles>

(c)<smiles>C=C/C(C)=C\CC=C(C)C</smiles>

(d)<smiles>CC1C=CC(C(C)C)=CC1</smiles>

(e)<smiles>CC12CCC(CC1)C(C)(C)O2</smiles>

(f)<smiles>C=CC(O)CCC=C(C)C</smiles>

(g)

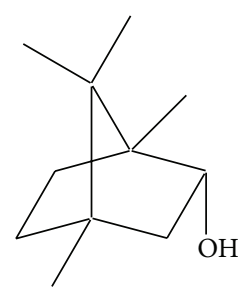

(h)<smiles>CC1=CCC(C(C)(C)O)CC1</smiles>

(i)<smiles>CC1=CC(=O)C(=C(C)C)CC1</smiles>

(k)<smiles>CC(=O)Oc1cc(C)ccc1C(C)C</smiles>

(1)<smiles>C=C(C)C1CCC2(C)OC2C1=O</smiles>

(m)

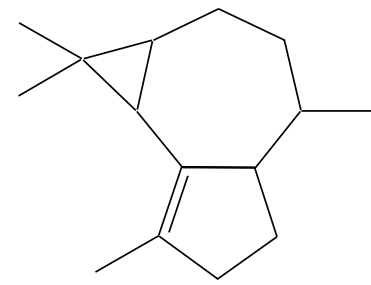

(n)

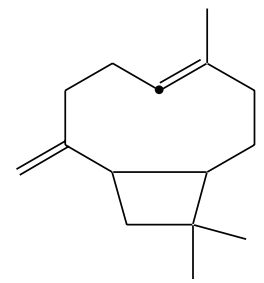

(o)<smiles>C=C(C)CCC=C(C)CCC1C=CC(=C)CC1C</smiles>

(p)<smiles>Cc1ccc2c(c1)C(C(C)C)CCC2C</smiles>

(q)

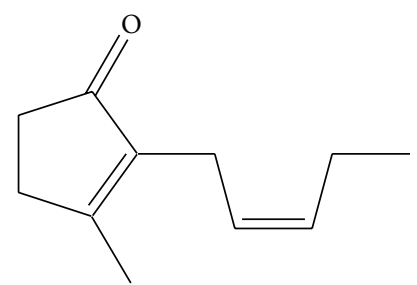

$(\mathrm{r})$

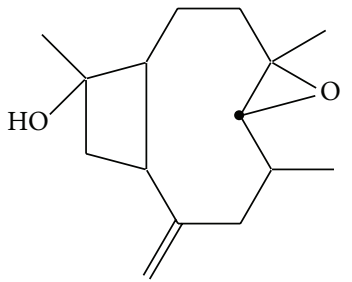

$(\mathrm{s})$

FiguRE 1: Structure of major compounds detected from M. longifolia essential oil. (a) $\alpha$-Pinene; (b) $\beta$-pinene; (c) limonene; (d) cis- $\beta$-ocimene; (e) $\delta$-terpinene; (f) 1,8-cineole; (g) linalool; (h) borneol; (i) $\alpha$-terpineol; (j) thymol; (k) piperitenone; (l) thymol acetate; (m) piperitenone oxide; (n) $\alpha$-gurjunene; (o) $\beta$-caryophyllene; (p) germacrene D; (q) calamenene; (r) cis-jasmone; (s) caryophyllene oxide.

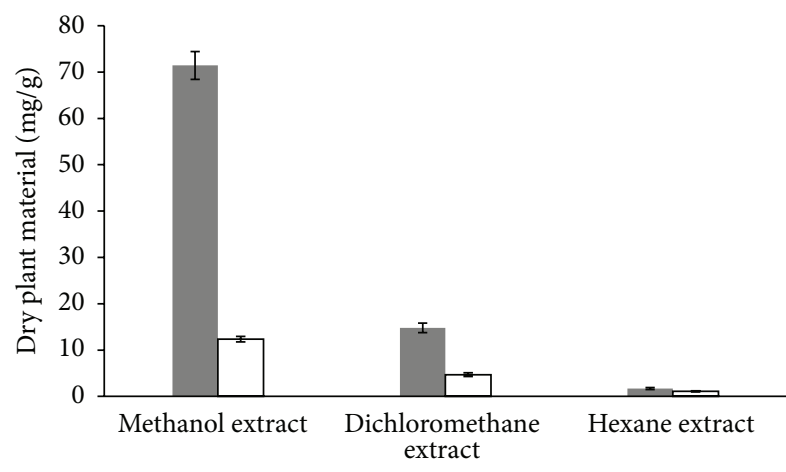

TPC (measured as gallic acid equivalent) TFC (measured as catechin equivalent)

FIGURE 2: Total phenolics (TP) and total flavonoids (TF) contents of $n$-hexane, dichloromethane, and methanol extracts of M. longifolia.

the amount of TF in methanol, dichloromethane, and hexane extracts was found to be $12.35,4.7$, and $1.1 \mathrm{mg} / \mathrm{g}$ acid of dry plant material, measured as catechin equivalent. The effect of different solvent systems on the amount of TP and TF was significant $(P<0.05)$. Methanol has been proven as effective solvent to extract phenolic compounds [6].
3.3.2. DPPH Radical Scavenging Assay. The ability of $M$. longifolia essential oil and different extract to donate proton to DPPH free radical and change its color from violet to yellow is accessed in this assay. Concentration of extracts and essential oil scavenging $50 \%$ of DPPH radical is shown in Table 3. $\mathrm{IC}_{50}$ value ranged from 6.70 to $33.3 \mu \mathrm{g} / \mathrm{mL}$. Greater $\mathrm{IC}_{50}$ value (maximum radical scavenging activity) was observed with methanol extract of $M$. longifolia, and lesser $\mathrm{IC}_{50}$ value was recorded with $n$-hexane extract. $\mathrm{IC}_{50}$ values of $M$. longifolia essential oil and dichloromethane extracts were found to be comparable with $\mathrm{IC}_{50}$ value of the piperitenone, a major compound of $M$. longifolia essential oil. IC $_{50}$ value of methanol extract is significantly $(P<0.05)$ better than hexane and dichloromethane extracts and essential oil and comparable with synthetic antioxidant, BHT.

\subsubsection{Antioxidant Activity Determination in Terms of Inhibi-} tion of Linoleic Acid Peroxidation. The antioxidants activity has also been assessed as ability to prevent the oxidation of linoleic acid. Therefore, inhibition of linoleic acid oxidation was also used to assess the antioxidant activity of $M$. longifolia extracts and essential oil. All extracts and essential oil exhibited appreciable inhibition of linoleic acid peroxidation (Table 3) ranging from 9.9 to $91.6 \%$. Methanol extract showed maximum antioxidant activity (91.6\%) followed by dichloromethane extract $(89.3 \%)$ which is comparable with 
TABLE 2: Chemical composition of M. longifolia essential oil.

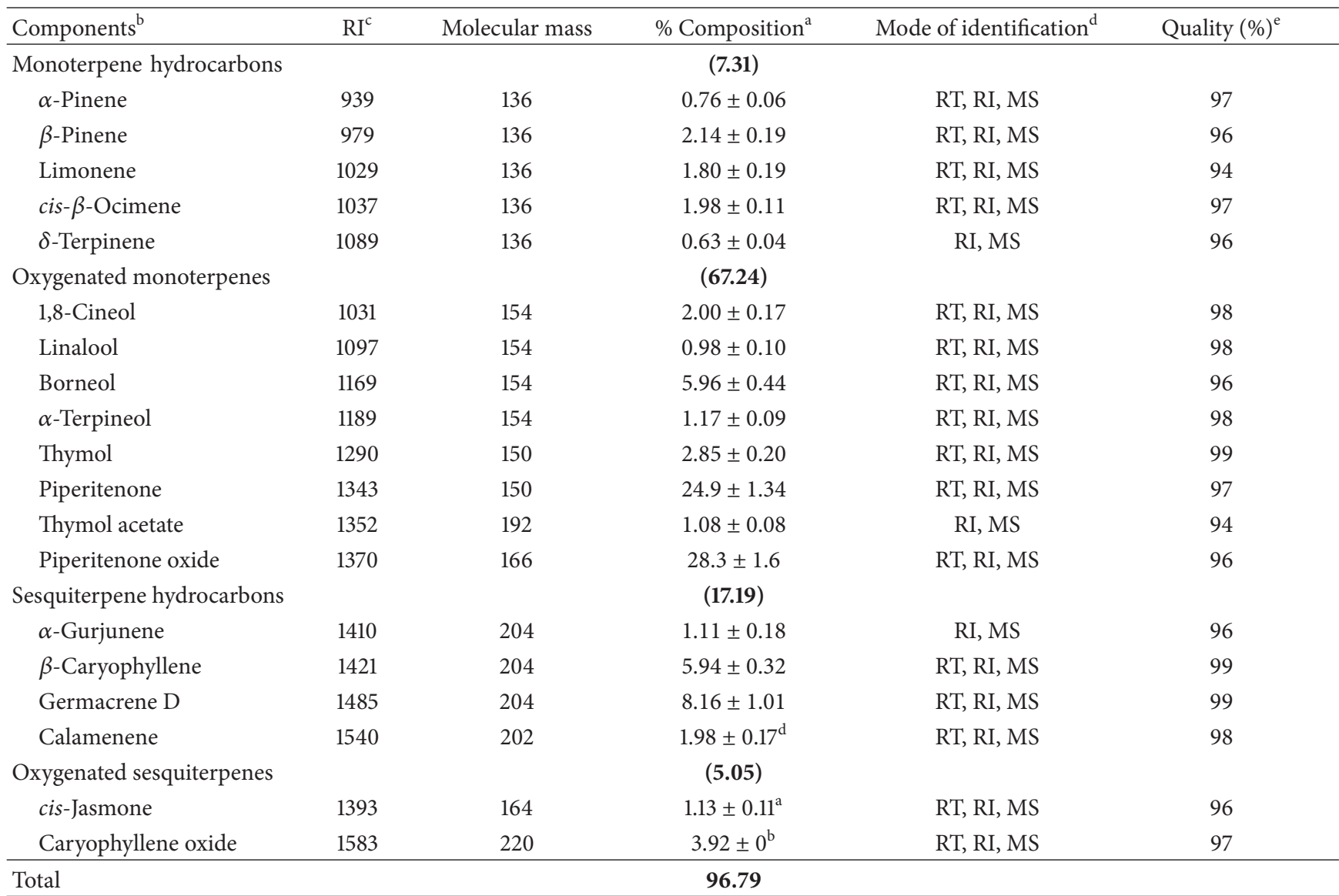

${ }^{\mathrm{a}}$ Values are mean \pm standard deviation of three samples of $M$. longifolia essential oil, analyzed individually in triplicate.

${ }^{\mathrm{b}}$ Compounds are listed in order of elution from a HP-5MS column; ${ }^{c}$ retention indices relative to $\mathrm{C}_{9}-\mathrm{C}_{24} n$-alkanes on the HP-5MS column; ${ }^{\mathrm{d}}$ mode of identifications; RT: identification based on retention time; RI: identification based on retention index; MS: identification based on comparison of MS data compared with those from the NIST02.L and WILEY7n.L mass spectral libraries; ${ }^{\mathrm{e}}$ matching percentage with the NIST02.L and WILEY7n.L mass spectral libraries.

TABLE 3: Antioxidant activity of M. longifolia essential oil and $n$ hexane, dichloromethane, and methanol extracts.

\begin{tabular}{lcc}
\hline \multirow{2}{*}{ Samples } & \multicolumn{2}{c}{ Antioxidant activity $^{*}$} \\
& $\begin{array}{c}\text { DPPH, } \mathrm{IC}_{50}, \\
\left(\mu \mathrm{g} \mathrm{mL}^{-1}\right)\end{array}$ & $\begin{array}{c}\text { Inhibition of linoleic } \\
\text { acid peroxidation }(\%)\end{array}$ \\
\hline Essential oil & $21.8 \pm 1.2^{\mathrm{c}}$ & $37.3 \pm 1.3^{\mathrm{c}}$ \\
$n$-Hexane extract & $33.3 \pm 1.7^{\mathrm{d}}$ & $9.9 \pm 0.7^{\mathrm{a}}$ \\
DCM extract & $21.2 \pm 1.7^{\mathrm{c}}$ & $89.3 \pm 2.9^{\mathrm{d}}$ \\
Methanol extract & $6.70 \pm 0.3^{\mathrm{a}}$ & $91.6 \pm 2.3^{\mathrm{d}}$ \\
Piperitenone & $22.7 \pm 1.5^{\mathrm{c}}$ & $31.3 \pm 2.1^{\mathrm{b}}$ \\
BHT & $9.90 \pm 0.2^{\mathrm{b}}$ & $90.9 \pm 2.7^{\mathrm{d}}$ \\
\hline
\end{tabular}

*Values are mean \pm standard deviation of three samples of each Thymus species, analyzed individually in triplicate. Mean followed by different superscript letters in the same column represents significant difference $(P<$ $0.05)$.

NT: not tested.

the activity of BHT standard (90.6\%). M. longifolia essential oil and hexane extract showed weaker antioxidant activity. Polar extract exhibited significantly $(P \leq 0.05)$ higher antioxidant activity than nonpolar extracts which might be due to the higher concentration of $\mathrm{TP}$ and $\mathrm{TF}$ contents [15].

\subsubsection{Antioxidant Activity Determination in Terms of Bleach-} ing of $\beta$-Carotene in Linoleic Acid System. Bleaching $\beta$ carotene with linoleic acid system as antioxidant activity of the M. longifolia essential oil and extracts is presented in Figure 3. The greater is the effectiveness of an antioxidant, the slower will be the colour depletion. In Figure 3 smaller decline in absorbance of $\beta$-carotene indicates a lower rate of oxidation of linoleic acid and higher antioxidant activity in the presence of $M$. longifolia methanol and dichloromethane extracts and BHT. Hexane extract and essential oil showed poor antioxidant activity.

\section{Conclusion}

Methanol extracts of Mentha longifolia exhibited excellent antioxidant activity and free radical scavenging capacity followed by dichloromethane extract, essential oil, and hexane 


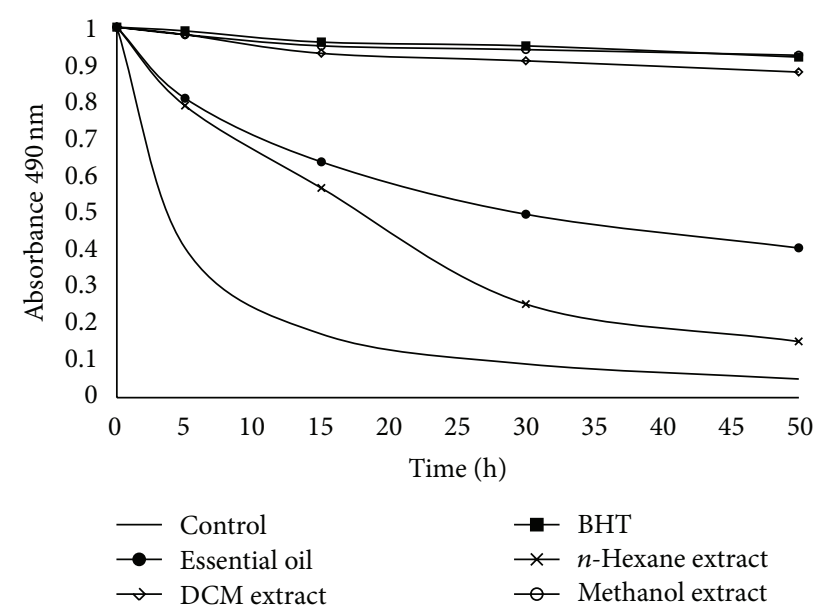

FIgURE 3: Antioxidant activity of $M$. longifolia essential oil and $n$-hexane, dichloromethane, and methanol extracts in terms of bleaching of $\beta$-carotene-linoleic acid emulsion.

extract. High TP and TF contents and antioxidant potential of $M$. longifolia extracts lead to its possible use as a food preservative. Moreover, they may be used in pharmaceutical and natural therapies for treatment of oxidative stress.

\section{Acknowledgment}

Grants supports by the Higher Education Commission (HEC), Islamabad, Pakistan, under the National Research Program for University (NRPU) scheme are highly acknowledged.

\section{References}

[1] A. I. Hussain, F. Anwar, S. T. H. Sherazi, and R. Przybylski, "Chemical composition, antioxidant and antimicrobial activities of basil (Ocimum basilicum) essential oils depends on seasonal variations," Food Chemistry, vol. 108, no. 3, pp. 986995, 2008.

[2] F. Shahidi and P. K. Wanasundara, "Phenolic antioxidants," Critical Reviews in Food Science abd Nutrition, vol. 32, no. 1, pp. 67-103, 1992.

[3] B. Sultana, F. Anwar, and R. Przybylski, "Antioxidant activity of phenolic components present in barks of Azadirachta indica, Terminalia arjuna, Acacia nilotica, and Eugenia jambolana Lam. trees," Food Chemistry, vol. 104, no. 3, pp. 1106-1114, 2007.

[4] D. Huang, O. U. Boxin, and R. L. Prior, "The chemistry behind antioxidant capacity assays," Journal of Agricultural and Food Chemistry, vol. 53, no. 6, pp. 1841-1856, 2005.

[5] S. A. S. Chatha, A. I. Hussain, J. Bajwa, and M. Sagir, "Antioxidant activity of different solvent extracts of rice bran at accelerated storage of sunflower oil," Journal of Food Lipids, vol. 13, no. 4, pp. 424-433, 2006.

[6] P. Siddhuraju and K. Becker, "Antioxidant properties of various solvent extracts of total phenolic constituents from three different agroclimatic origins of drumstick tree (Moringa oleifera Lam.) leaves," Journal of Agricultural and Food Chemistry, vol. 51, no. 8, pp. $2144-2155,2003$.
[7] A. I. Hussain, F. Anwar, S. A. S. Chatha, A. Jabbar, S. Mahboob, and P. S. Nigam, "Rosmarinus officinalis essential oil: antiproliferative, antioxidant and antibacterial activities," Brazilian Journal of Microbiology, vol. 41, no. 4, pp. 1070-1078, 2010.

[8] A. I. Hussain, F. Anwar, P. S. Nigam, M. Ashraf, and A. H. Gilani, "Seasonal variation in content, chemical composition and antimicrobial and cytotoxic activities of essential oils from four Mentha species," Journal of the Science of Food and Agriculture, vol. 90, no. 11, pp. 1827-1836, 2010.

[9] A. I. Hussain, F. Anwar, S. Rasheed, P. S. Nigam, O. Janneh, and S. D. Sarker, "Composition, antioxidant and chemotherapeutic properties of the essential oils from two Origanum species growing in Pakistan," Revista Brasileira de Farmacognosia, vol. 21, no. 6, pp. 943-952, 2011.

[10] F. Anwar, A. I. Hussain, S. T. H. Sherazi, and M. I. Bhanger, "Changes in composition and antioxidant and antimicrobial activities of essential oil of fennel (Foeniculum vulgare Mill.) fruit at different stages of maturity," Journal of Herbs, Spices and Medicinal Plants, vol. 15, no. 2, pp. 187-202, 2009.

[11] Y. Massada, Analysis of Essential Oils by Gas Chromatography and Mass Spectrometry, John Wiley \& Sons, New York, NY, USA, 1976.

[12] R. P. Adam, Identification of Essential Oils Components by Gas Chromatography/Quadrupole Mass Spectroscopy, Allured Publishing, Carol Stream, Ill, USA, 2001.

[13] F. Anwar, M. Ali, A. I. Hussain, and M. Shahid, "Antioxidant and antimicrobial activities of essential oil and extracts of fennel (Foeniculum vulgare Mill.) seeds from Pakistan," Flavour and Fragrance Journal, vol. 24, no. 4, pp. 170-176, 2009.

[14] K. Vagionas, K. Graikou, O. Ngassapa, D. Runyoro, and I. Chinou, "Composition and antimicrobial activity of the essential oils of three Satureja species growing in Tanzania," Food Chemistry, vol. 103, no. 2, pp. 319-324, 2007.

[15] A. I. Hussain, S. A. S. Chatha, S. Noor et al., "Effect of extraction techniques and solvent systems for the extraction of antioxidant components from peanut (Arachis hypogaea L.) Hulls," Food Analytical Methods, vol. 5, no. 4, pp. 890-896, 2012.

[16] S. Iqbal, M. I. Bhanger, and F. Anwar, "Antioxidant properties and components of some commercially available varieties of rice bran in Pakistan," Food Chemistry, vol. 93, no. 2, pp. 265272, 2005.

[17] A. M. Viljoen, S. Petkar, S. F. van Vuuren, A. C. Figueiredo, L. G. Pedro, and J. G. Barroso, "The chemo-geographical variation in essential oil composition and the antimicrobial properties of "wild mint"-Mentha longifolia subsp. polyadena (Lamiaceae) in Southern Africa," Journal of Essential Oil Research, vol. 18, pp. 60-65, 2006.

[18] M. Gulluce, F. Sahin, M. Sokmen, H. Ozer, D. Daferera, and A. Sokmen, "Antimicrobial and antioxidant properties of the essential oils and methanol extract from Mentha longifolia L. ssp. longifolia," Food Chemistry, vol. 103, no. 4, pp. 1449-1456, 2007. 

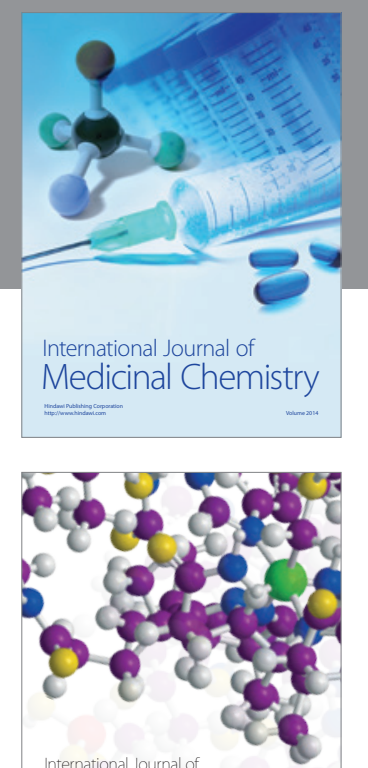

\section{Carbohydrate} Chemistry

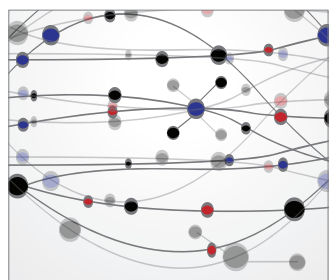

The Scientific World Journal
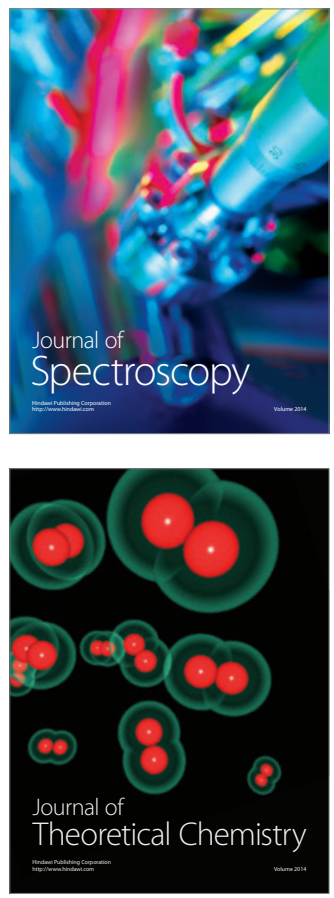
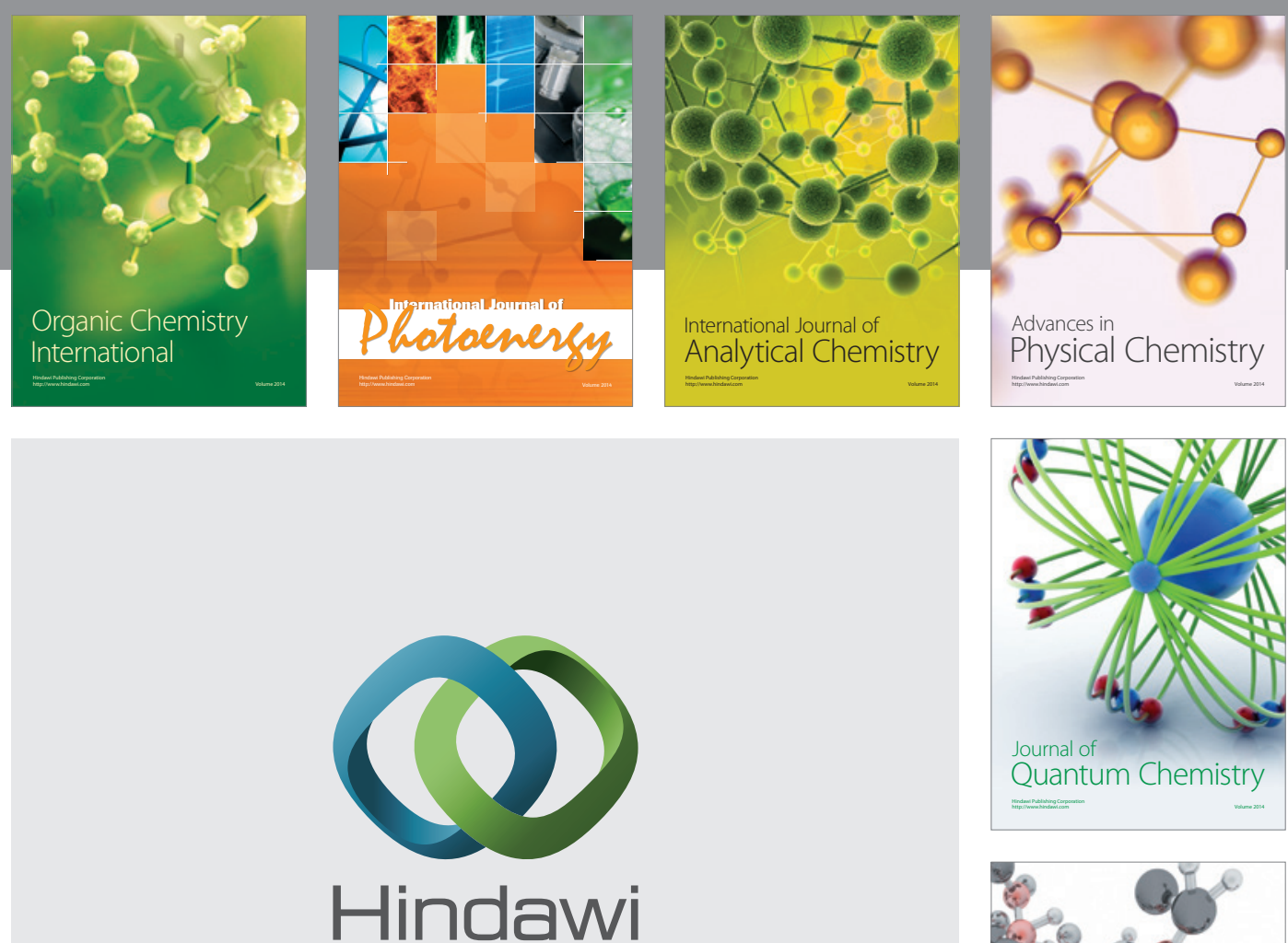

Submit your manuscripts at

http://www.hindawi.com

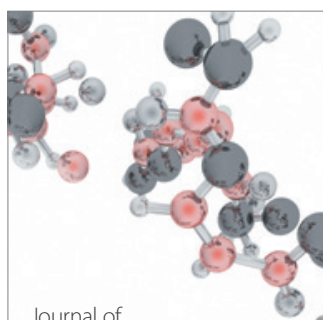

Analytical Methods

in Chemistry

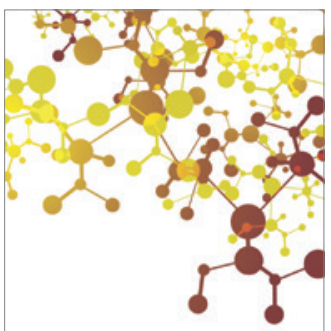

Journal of

Applied Chemistry

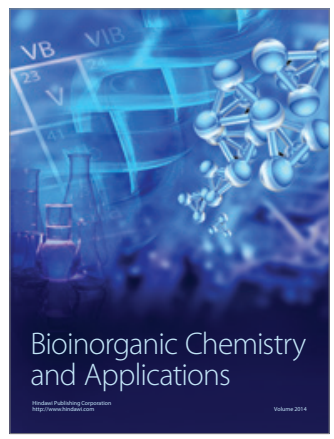

Inorganic Chemistry
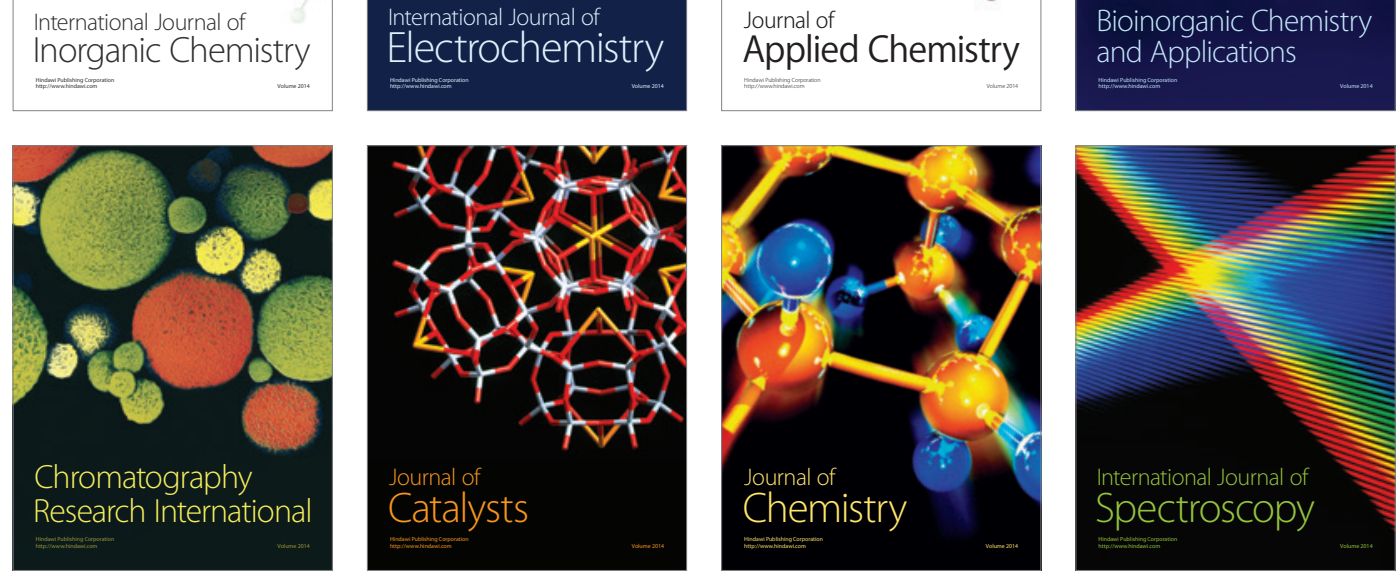